\title{
BMJ Open Analysing actual prices of medical products: a cross-sectional survey of Dutch hospitals
}

\author{
Anouk den Ambtman (D) , ${ }^{1,2}$ Joris Knoben, ${ }^{2}$ Dana van den Hurk, ${ }^{2}$ \\ Mark Van Houdenhoven ${ }^{1,2}$
}

To cite: den Ambtman A, Knoben J, van den Hurk D, et al. Analysing actual prices of medical products: a cross-sectional survey of Dutch hospitals. BMJ Open 2020;10:e035174. doi:10.1136/ bmjopen-2019-035174

- Prepublication history for this paper is available online. To view these files, please visit the journal online (http://dx.doi. org/10.1136/bmjopen-2019035174).

Received 28 0ctober 2019 Revised 22 January 2020 Accepted 23 January 2020
Check for updates

(C) Author(s) (or their employer(s)) 2020. Re-use permitted under CC BY-NC. No commercial re-use. See rights and permissions. Published by BMJ.

${ }^{1}$ Board of Directors, Sint Maartenskliniek, Nijmegen, The Netherlands

${ }^{2}$ Institute for Management Research, Radboud University, Nijmegen, The Netherlands

Correspondence to Dr Anouk den Ambtman; a.denambtman@ maartenskliniek.nl

\section{ABSTRACT}

Objectives To assess whether there is a difference between the net prices of medical products used by Dutch hospitals and, if there is, how this difference can be explained.

Design Cross-sectional self-administered electronic survey.

Setting We surveyed the prices paid for 17 commonly used medical products, such as pacemakers, gloves and stents in 38 Dutch hospitals (including general, specialised and academic hospitals) in 2017. Hospitals voluntarily and anonymously provided these data and received a personalised free benchmark tool in return. This tool provides information about the variance in prices of the medical products they buy.

Participants 38 out of 79 hospitals entered and completed the study.

Primary and secondary outcome measures Actual price paid excluding Value Added Tax (VAT) per item, the order size per year, total spending for an assortment group and total spending for all products purchased from a specific supplier were measured.

Results We found large price variations for the medical products surveyed (average coefficient of variation of $71 \%)$. In general, these differences were hard to explain (average $\mathrm{R}^{2}$ of $26 \%$ ). Only purchasing volume (for 8 out of 17 products) was significantly associated with the net price paid by a hospital. Total spending for an assortment group (in euros with a specific supplier) and total spending (for all products in euros with a specific supplier) were not related to the net price paid.

Conclusions We conclude that only purchasing volume is associated with lower prices paid. Total spending for an assortment group and total spending for all products purchased from a specific supplier are not. These results are in stark contrast to expectations based on economic theory. Other sources of differences in bargaining power might explain these findings. Further research might involve comparing prices across countries.

\section{INTRODUCTION}

Rising healthcare costs around the world are becoming increasingly problematic for the affordability and access to healthcare. This paper focuses on healthcare costs in highincome Western countries. In these countries, it is striking that medical suppliers have a net

\section{Strengths and limitations of this study}

- Half of the Dutch hospitals participated, which is a representative sample of the Dutch hospital population.

- Both low and high physician preference products were analysed.

- Three economic variables were used to explain net price differences.

- This Hospital Purchase Benchmark study is an intracountry comparison of actual price data of medical products and none cross-country price comparisons were made.

- The dataset only focuses on medical products and, in fact, a limited number of these products.

profit margin of 20\%-25\%, whereas hospitals typically have a net profit margin of $5 \%-10 \%^{1}$ Why are medical suppliers able to make such high profits? One explanation could be that hospitals lack up-to-date and accurate information about the actual prices paid by other hospitals for the same products. With this information, they could develop a more effective procurement and purchase strategy. The absence of such information could explain why hospitals pay different prices for the same medical product from the same supplier, as is the case for coronary stents. ${ }^{23}$ The medical products market features a system based on discounts compared with listed prices. Nondisclosure agreements (NDAs) are regularly applied to prevent information being shared between hospitals. By preventing information sharing, the information asymmetry between suppliers and hospitals is reinforced. Medical suppliers thus have more market power than hospitals. ${ }^{1}$ This situation is characterised by a lack of transparency where 'suppliers negotiate different contracts with different buyers, potentially with widely varying prices, and a buyer typically has limited information regarding other buyer's contracts' (Grennan, p2) ${ }^{4}$ This deliberate information asymmetry 
between suppliers and buyers leads to an opaque price market. In this research, we focus on the information asymmetry between hospitals and medical suppliers. We hypothesise that information asymmetry reduces hospitals' bargaining ability, defined as 'the ability to reach a more favourable point within the range determined by costs, willingness to pay and competition', ${ }^{2}$ resulting in price variation between hospitals. Moreover, we hypothesise that the price variation will be higher for products that are preferred by physicians. The hospital's purchasing department regularly purchases medical products that are used by physicians. However, the medical products market is characterised by business-tophysician and not business-to-business arrangements. Physician preference items (PPIs) are purchased by hospitals, but 'physicians (surgeons) (...) determine which device to use for a particular patient and procedure' (Montgomery and Schneller, p308). ${ }^{5}$ Examples of PPIs are implants and cardiac stents. ${ }^{5}$ This one-to-one relationship between suppliers and physicians could undermine the bargaining position of hospitals and might explain price differences. ${ }^{67}$

Several studies have focused on the formal list prices of single medical products (such as stents, see, eg, Grennan and Swanson ${ }^{4}$ ) and on price variance in medicine in general, ${ }^{89}$ of which one zooms in on the limited set of net prices of cancer drugs. ${ }^{10}$ Vogler et al ${ }^{11}$ researched the prices of cancer drugs in high-income countries and found a variation between $28 \%$ and $388 \%$ between the highest and lowest priced country. To our knowledge, there are no countryspecific studies that estimate and structurally compare the variance in actual prices paid for medical products. In this study, we surveyed the actual prices of 17 commonly used medical products in about half of all Dutch hospitals. In order to analyse price variations for medical products and thereby study the information asymmetry between medical suppliers and hospitals (buyers), ${ }^{4}$ we created a self-administered survey. In the end, the aim is to reduce the information asymmetry and to find a way to increase price transparency. The results of the survey were compiled and visualised in the Hospital Purchase Benchmark. The Hospital Purchase Benchmark is meant to be a catalyst for reducing the information asymmetry and initiating change towards more affordable and accessible healthcare. We used data from this Hospital Purchase Benchmark to assess the variance in the net purchase prices of 17 medical products for Dutch hospitals. We assessed whether this price variation is related to the degree of physician preference and to what extent the prices paid are associated with the volume of the products purchased, total spending for an assortment group and total spending for all products purchased from a specific supplier. We focused on these elements as proxies for bargaining power, and therefore price differences, in 'normal' markets in which prices are transparent. ${ }^{12}$

\section{METHODS}

\section{Selection of medical products}

To create the benchmark tool, we selected a broad product portfolio of 17 products. These products are distinct, high-profile, well-known commodities with a high turnover originating from different types of suppliers. We selected products based on low and high 'physician preference'. Implants were categorised as items highly preferred by physicians according to the literature. ${ }^{5}$ The complete categorisation of products was also checked with key medical staff (eg, a strategic purchaser and the hospital Chief Executive Officer (CEO)). Table 1 provides an overview of the products chosen, their generic and specific characteristics and their global trade item numbers, which enable the comparability of products.

\section{Purchasing context and selection of hospitals}

The Netherlands has 79 hospitals, of which 8 are academic hospitals. All of these hospitals are small, especially in an international perspective and compared with the size of the main suppliers of medical products. Nevertheless, Dutch hospitals purchase medical products on a decentralised level. This means each hospital is able to negotiate with medical suppliers independently. There is slight difference between two types of hospitals with regard to the way of tendering. Academic hospitals within the Netherlands have to use European tenders to select medical suppliers. General and specialised hospitals can follow the process of European tendering but have more leeway to deviate from this process. Given this difference, we control for possible differences between academic and other hospitals in our analyses. The Dutch purchasing context is characterised by a strong focus on three parameters: cost reduction, risk management and service quality.

We selected hospitals based on a convenience sampling approach, ${ }^{13}$ including general, specialised and academic hospitals in the Netherlands. Gaining confidence and trust from the selected hospitals was a time-consuming process. The hesitation to participate was due to the hospitals' perceived vulnerable position in relation to global medical suppliers. One of the authors personally contacted members of the top management of all Dutch hospitals to participate in the survey study and used NDAs where desired. The top managers subsequently asked the purchasers of their hospital to provide the requested data for the survey. Half of the Dutch hospitals, 38 out of a total of $79,{ }^{14}$ voluntarily provided net purchase data for the selected 17 products between January 2017 and May 2018. Only the research team knew which hospitals were included in the sample. We anonymised the data and then used these data for further analysis. Approval of our local ethics committee was not required as this research neither involved patients nor the members of the general public.

\section{Patient and public involvement}

In this study, the database we used was constructed from collected purchasing data through a cross-sectional selfadministered electronic survey among Dutch hospitals. No patients were directly involved in the design, planning and conception of this study. 


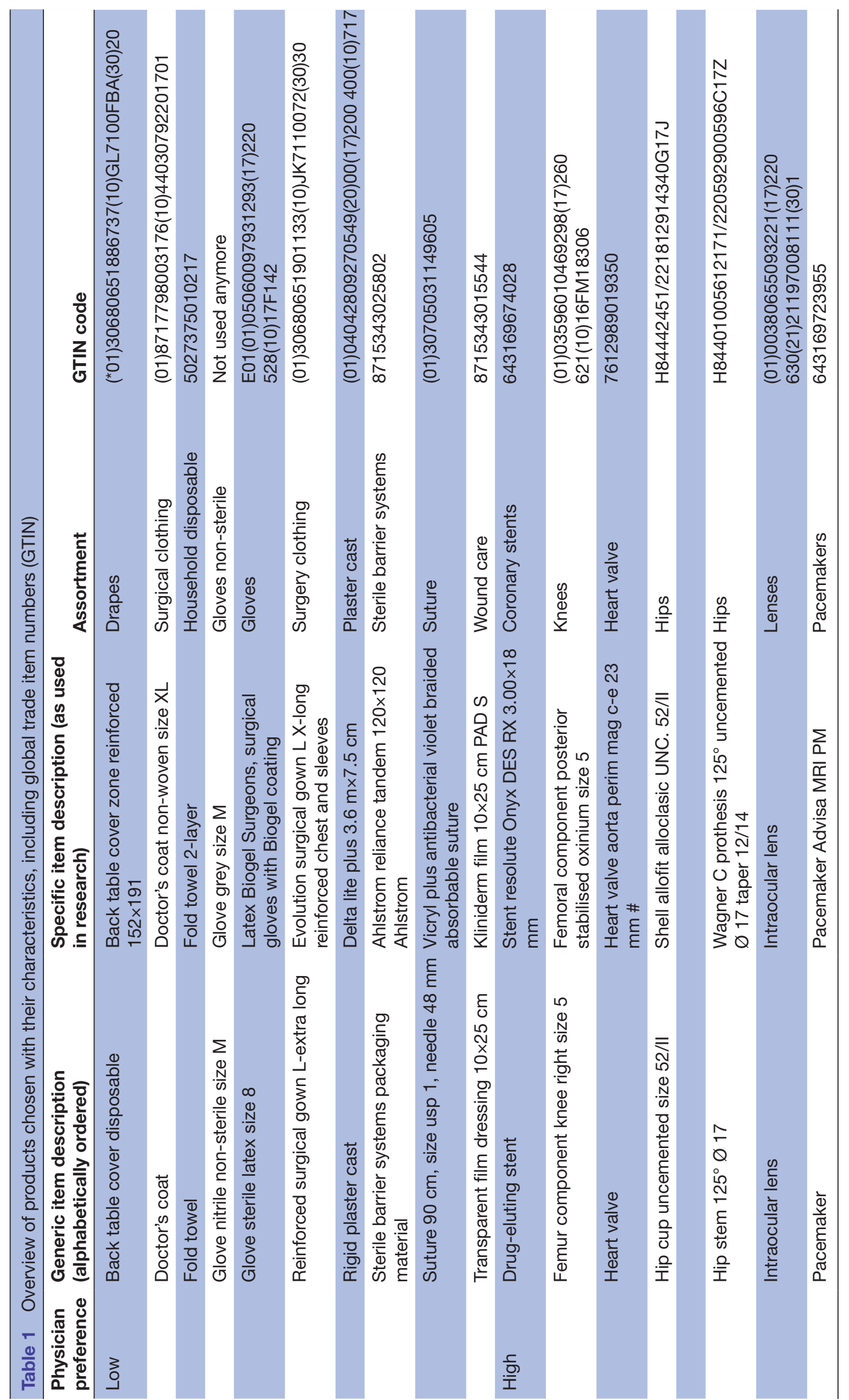




\section{Survey design}

For each product we determined the actual price paid excluding VAT per item, the order size per year, total spending for an assortment group and total spending for all products purchased from a specific supplier. We used a survey (in table format) in Microsoft Excel to collect net price data from 2017.

\section{Hospital Purchase Benchmark}

The Hospital Purchase Benchmark is a consumer-based, not-for-profit initiative designed by and for hospitals. We offered hospitals that participated in the study the Hospital Purchase Benchmark as a free tool which they could use to access the relevant purchase benchmark data related to medical products. Hospitals could use this tool to identify their relative position compared with other Dutch hospitals that use similar or equivalent medical products. We trusted in the expertise of the hospitals in selecting the best equivalent product in cases where they did not use the exact same products being surveyed, for example, an equivalent implant from another medical supplier. The benchmark provides graphs about price versus purchasing volume, total spending for an assortment group and total spending for all products purchased from a specific supplier. We gave hospitals access to the Hospital Purchase Benchmark in exchange for information about their purchase orders for the 17 predefined items. In other words, hospitals 'paid' with their data and received access to the Hospital Benchmark in return. The participating hospitals only received access to benchmark data available for the category for which they had provided purchasing data. Participants were allowed to iteratively provide more data. They were able to compare their actual prices paid (at the time when the data were collected) with other local and national hospitals to gain insight into their purchasing performance for medical products from different suppliers. Organisational names were anonymised within the benchmark tool and other participants were unable to relate data points to specific hospitals.

In some cases, hospitals that provided price data did not report data for purchasing volume (2 cases), the total spending for an assortment group (4 cases) or the total spending for all products purchased from a particular supplier (13 cases). In these cases, we used publicly available information from annual reports to determine the total revenue of each hospital. Based on the known data for the respective hospital and annual report data, we calculated predicted values and used these in our subsequent analyses.

\section{DATA ANALYSIS AND RESULTS}

All calculations and analyses were performed with Microsoft Excel for Windows (V.14.0.7194.5), IBM SPSS Statistics (V.25) and Stata (V.13.1). Table 2 shows the surveyed net prices of the 17 products that we categorised based on physician preference. On the basis of this information, various measures of price variation discussed in the literature could have been calculated. ${ }^{15}$ However, many of these measures are only useful to characterise variations in price over time ${ }^{16}$ and are, therefore, not applicable to our study. Moreover, since the price variation was compared across products categories that vary substantially in their absolute price, a measure of variation that is proportional to the mean was required. ${ }^{17}$ Three main measures are commonly used in such a situation: (1) Gini coefficients, (2) Theil's information theoretic measure and (3) coefficients of variation. ${ }^{15}$ The third measure, the coefficient of variation, is the most widely used in price variation studies. ${ }^{18} \mathrm{We}$, therefore, chose this measure of price variation. For robustness, we also calculated the Gini coefficients and Theil's information theoretic measure. We found that they correlate extremely strongly with the coefficient of variation $(r>0.98)$. As such, the choice for a specific price variation measure did not influence our results.

First, the data presented in table 2 show that net prices for identical medical products vary significantly across the hospitals surveyed. The average coefficient of variation was $71 \%$, with a maximum of $357 \%$ for sterile barrier systems packing material and a minimum of $19 \%$ for reinforced surgical gowns. Interestingly, the price variations are not systematically associated with the degree of physician preference for the product. If anything, there is a larger price variation for low physician preference products than for high physician preference products (the average coefficient of variation is $84 \% 49 \%$ ). However, this difference is statistically insignificant due to large variations in price variation within each category. The boxplot in figure 1 illustrates this finding by displaying the price variance (normalised based on the mean and displayed with the median $=0$ and the $\mathrm{SD}=1$ ) for each product ordered according to physician preference.

Based on the data presented in table 2, we estimated several regression models. Specifically, we estimated the effects on the price paid for each specific product of the (1) number of products purchased by the hospital, (2) total spending on the product category by the hospital, (3) total spending at this supplier by the hospital and (4) whether the hospital is an academic hospital or not. Given that our dependent variable is a scale variable, we used Ordinary Least Squares (OLS) regressions. Since the exact distribution of our dependent variable differs between products (ie, it is normally distributed for some products but skewed for others), we used robust standard errors in all of our models. Moreover, to ensure the robustness of our results, we also re-estimated all our models using log-transformed variables. The results of these analyses are identical in terms of signs and significances of coefficients as the ones reported in the paper and can be obtained from the authors on request.

The results presented in table 3 show purchasing a higher number of products resulted in a lower price per product for 15 of the 17 products. For 8 of these 15 products, the effect is statistically significant at the $90 \%$ level or higher. 


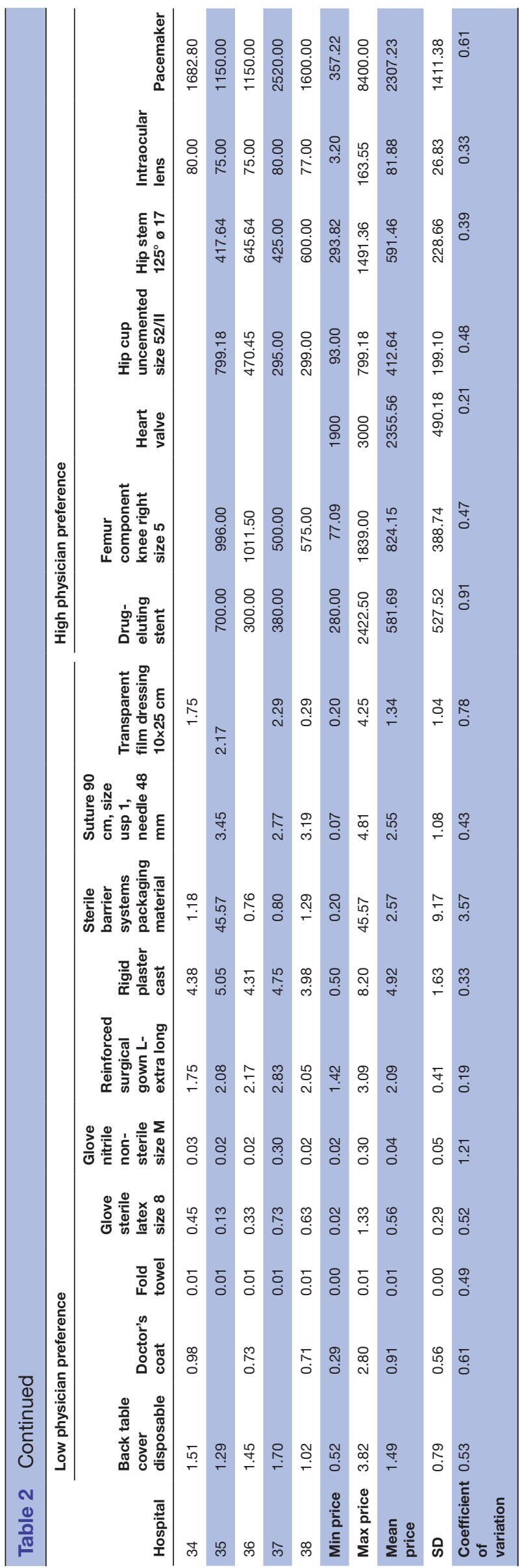

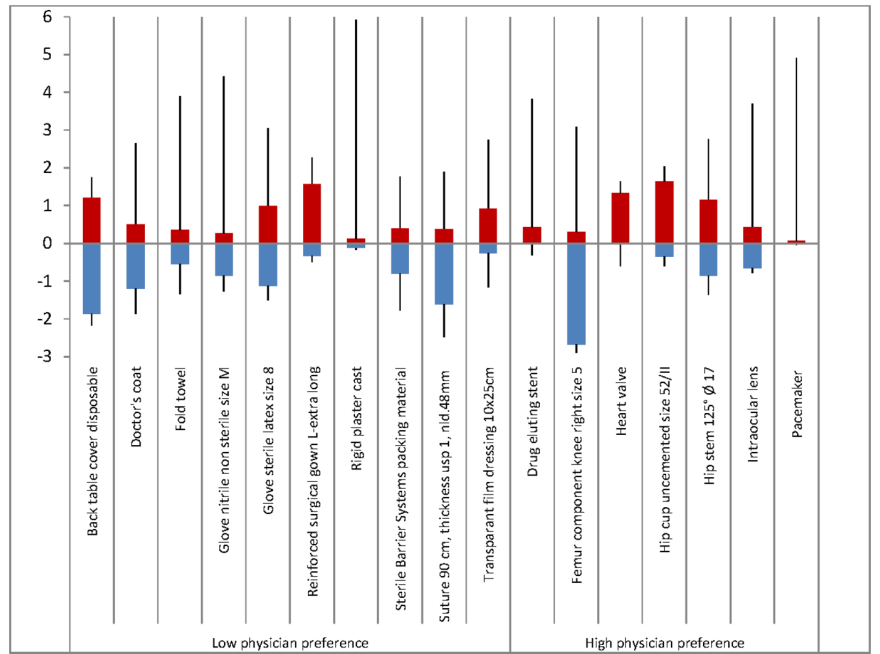

Figure 1 Boxplot of net price ranges of medical products (excl. VAT) ranked on the extent of physician preference and normalized (based on median set to zero and standard deviation set to one), as of January 2017, for 38 Dutch hospitals.

These results are largely consistent with expectations, as purchasing larger volumes are generally associated with a stronger bargaining position. However, for total spending on the product category and for the total amount spent with the supplier, the results are not what we expected. Here, the effects we find are often positive and, in some cases, even statistically significantly positive. So, our conclusion is that higher levels of spending on a specific product assortment and a higher amount spent with a specific supplier do not lead to lower prices. Finally, we find no consistent effect of being an academic hospital on the price paid for medical products. The effect of this variable is positive in some cases and negative in others with an average effect of 0 .

All in all, the models explain a relatively small amount of the differences in prices paid by hospitals. The average $\mathrm{R}^{2}$ is only 0.26 , indicating that $74 \%$ of the price differences are not accounted for by our models. Combined with the fact that only the number of products bought has the expected negative effect on prices, we conclude that the market for medical products does not function as a regular market where there is a low variation in prices and price variations can be explained by differences in bargaining power. Interestingly, the large price variation in medical products also does not seem to be systematically associated with the degree of physician preference.

\section{DISCUSSION}

The net price variance of 17 medical products in Dutch hospitals is substantial and, in some cases, enormous. Various economists ${ }^{12}$ argue that purchasing volume, total spending for an assortment group and total spending for all products from a specific supplier should be negatively correlated to the price paid, as these factors are proxies for bargaining power. However, we conclude that of these factors only the purchasing volume is negatively associated 
with prices paid and the remaining unexplained price variation is substantial (ie, $74 \%$ on average).

Price mechanisms in the medical products market are often counterintuitive and contrary to expectations based on economic theory. The results imply that the pricing of medical products is opaque, and it remains unclear how price and discount mechanisms in this market work, even in a small country such as the Netherlands. An important reason for this seems to be that hospitals are simply not aware of what other hospitals are paying for medical products. Despite the huge price variations, we found that the vast majority of the hospitals believe they are paying the lowest price. This widespread belief is certainly not supported by our findings. Moreover, the role of the physician preference politics remains vague.

A limitation of our study is that we do not know what explains the remaining $74 \%$ of the price variation observed. However, we can rule out the influence of certain factors due to the set-up of our study. For example, we can say that open source and international comparisons of prices of medical products are rare to due secrecy concerning those prices. ${ }^{6}$ As a result, such comparisons are based on list prices and not actual prices paid and are therefore rather uninformative. They are therefore unlikely to be helpful to hospitals in their negotiations with medical suppliers. ${ }^{8}$ Moreover, competition between medical suppliers could influence the prices paid for a specific product but this competition should exert a general downward pressure on the price of a product and should not lead to price variation between hospitals within a product category. The same holds for patenting and the life cycle of medical products. Even though it is speculative, we believe that the opaque market conditions for medical products results in a situation in which procurement skills and the social capital of purchasers play a large role.

\section{Managerial implications}

The actual prices paid for medical products are often secret, due to NDAs between medical suppliers and hospitals. Uniquely, the Hospital Purchase Benchmark tool used in this study is based on actual prices. This provides the purchasing departments of hospitals with crucial price information to facilitate strategic decisions. The benchmark creates a more level playing field between hospitals and medical suppliers. Thanks to the use of actual price information, it increases price transparency. This information strengthens the bargaining position of hospitals, because they can determine their relative price position compared with other hospitals within the same country, allowing the market to function more effectively. The necessity and continuity of the Hospital Purchase Benchmark is thus of crucial importance, since the enormous net price variance and the lack of applicability of standard economic rules make the medical products market opaque. The Hospital Purchase Benchmark is currently the only mechanism that gives participating Dutch hospitals extensive insight into their bargaining position as well as the possibility to strengthen this position, thereby creating an opportunity to 
improve the market for medical products. Since healthcare costs are continuously increasing, it is important to note that the use of benchmarking tools such as the Hospital Purchase Benchmark can counteract the upwards spiral of increasing costs and eventually start to reduce them. Somewhat counterintuitively, we observed larger price variations for low physician preference products than for high physician preference products. We therefore recommend that strategic purchasers pay particular attention to commodity goods.

\section{Limitations and future research}

Despite the fact that our study makes an important contribution by providing several new insights, it naturally also has its limitations. First, it only focuses on the Dutch context. Exploring-and comparing-the price variance mechanisms in an international setting is necessary, because the international market is subject to diverse legislation, which makes it even more opaque. We propose cross-country price comparisons including actual prices paid and the continued use of the Hospital Purchase Benchmark to open up price transparency.

Second, the issue of transparency at the market level also translates to the intraorganisational level. The actual purchase of products within the hospital is usually done by the purchasing department and not by actors on the shop floor, such as physicians. This makes it interesting to further investigate the influence of physician preferences on price and discount mechanisms at the intraorganisational level.

Third, acquiring the net price data of half of the Dutch hospitals by means of a cross-sectional survey was challenging and using a longitudinal design was impossible. Many hospitals were initially reluctant to participate in the research because they were hesitant to share data due to NDAs signed with medical suppliers and the risk of a lawsuit. They also felt that participation in this research might harm their discount agreements with medical suppliers. This situation probably stems from the difference in power between hospitals and medical suppliers, which is an avenue for future research. Medical suppliers can make shrewd use of the diversity and confidentiality created by NDAs. Due to the NDAs, they are able to prevent information being shared between hospitals, which make it difficult for purchasers to negotiate fair prices. Future research could focus on thoroughly understanding the power balance between hospitals and medical suppliers.

Finally, our dataset only focuses on medical products and, in fact, a limited number of these products. Future research could add broader product portfolios or even product assortment groups such as implants, suture material or medicines. We therefore suggest extending and deepening the Hospital Purchase Benchmark by including information from different product assortments, hospitals participating in purchasing organisations and collaborative purchasing partnerships and markets, such as those for medicines. Further development of the Hospital Purchase Benchmark is needed to allow hospitals worldwide to compare negotiated net prices on a wide range of medical products and medicines. This research is the start of an initiative by and for hospitals to use a benchmark as a crucial tool for partially resolving the current information asymmetry between medical suppliers and hospitals. It will hopefully strengthen the position of nationally oriented hospitals compared with medical suppliers that operate globally.

Notwithstanding these limitations and needs for future research, hospital purchase benchmarks are of growing importance to open up price transparency without NDAs, which translates directly in bringing about change to secure more affordable and accessible healthcare in the future.

Acknowledgements The authors thank all the participating hospitals.

Contributors AdA was the lead author of this article and was supported in fine tuning the writing by DvdH and JK. AdA and DvdH conducted the exploratory data analyses. JK conducted the multivariate analysis. MVH monitored the data collection and the writing process. All authors provided and discussed feedback.

Funding The authors have not declared a specific grant for this research from any funding agency in the public, commercial or not-for-profit sectors.

Competing interests None declared.

Patient consent for publication Not required.

Provenance and peer review Not commissioned; externally peer reviewed.

Data availability statement No additional data available.

Open access This is an open access article distributed in accordance with the Creative Commons Attribution Non Commercial (CC BY-NC 4.0) license, which permits others to distribute, remix, adapt, build upon this work non-commercially, and license their derivative works on different terms, provided the original work is properly cited, appropriate credit is given, any changes made indicated, and the use is non-commercial. See: http://creativecommons.org/licenses/by-nc/4.0/.

\section{ORCID iD}

Anouk den Ambtman http://orcid.org/0000-0002-3910-0290

\section{REFERENCES}

1 Gupta Strategists. Winst in de Nederlandse zorgsector, 2017.

2 Grennan M. Bargaining ability and competitive advantage: empirical evidence from medical devices. Manage Sci 2014;60:3011-25.

3 Vellez M. Determinants of price discrimination in the acquisition of medical devices. In: Paper CW, ed. CEIS working paper, 2012.

4 Grennan M, Swanson A. Transparency and negotiated prices: the value of information in hospital-supplier bargaining. National Bureau of Economic Research, 2016.

5 Montgomery K, Schneller ES. Hospitals' strategies for orchestrating selection of physician preference items. Milbank Q 2007;85:307-35.

6 Lerner JC, Fox DM, Nelson T, et al. The consequence of secret prices: the politics of physician preference items. Health Aff 2008;27:1560-5

7 Pauly MV, Burns LR. Price transparency for medical devices. Health Aff 2008;27:1544-53.

8 Hahn RW, Klovers KB, Singer HJ. The need for greater price transparency in the medical device industry: an economic analysis. Health Aff 2008;27:1554-9.

9 lacocca K, Sawhill J, Zhao Y. Why brand drugs priced higher than generic equivalents. Int J Pharm Healthc Mark 2015;9:3-19.

10 van Harten WH, Wind A, de Paoli P, et al. Actual costs of cancer drugs in 15 European countries. Lancet Oncol 2016;17:18-20.

11 Vogler S, Vitry A, Babar Z-U-D. Cancer drugs in 16 European countries, Australia, and New Zealand: a cross-country price comparison study. Lancet Oncol 2016;17:39-47.

12 Smith A. The invisible hand. London: Penguin Group, 2009.

13 Field A. Discovering statistics using IBM SPSS statistics. 4 ed. London: Sage Publications Ltd, 2013.

14 RIVM. Aantal organisaties voor medisch specialistische zorg, 2018. Available: https://www.volksgezondheidenzorg.info/onderwerp/ ziekenhuiszorg/cijfers-context/aanbod\#node-aantal-instellingenvoor-medisch-specialistische-zorg 
15 Smithson M. On relative dispersion: a new solution for some old problems. Qual Quant 1982;16:261-71.

16 Andersen TG, Bollerslev T, Diebold FX, et al. Modeling and forecasting realized volatility. Econometrica 2003;71:579-625.
17 Bland JM, Altman DG. Statistics notes: measurement error proportional to the mean. BMJ 1996;313:106.

18 Bedeian AG, Mossholder KW. On the use of the coefficient of variation as a measure of diversity. Organ Res Methods 2000;3:285-97. 